Article

\title{
Ultimate Meaning: We Don't Have It, We Can't Get It, and We Should Be Very, Very Sad
}

\author{
Rivka Weinberg \\ Scripps College; rivka_weinberg@scrippscollege.edu \\ Submitted: 28 May 2020, accepted: 21 October 2020, published: 25 April 2021
}

\begin{abstract}
Life is pointless. That's not okay. I show that. I argue that a point is a valued end and that, as agents, it makes sense for us to want our efforts and enterprises to have a point. Valued ends provide justifying reasons for our acts, efforts, and projects. I further argue that ends lie separate from the acts and enterprises for which they provide a point. Since there can be no end external to one's entire life since one's life includes all of one's ends, leading and living one's life as a whole cannot have a point. Finally, I argue that since we live our lives and structure our living-a-human-life efforts both in parts and as a whole, it is fitting to be sad to recognize that leading and living a life is pointless. My discussion helps make sense of the literature that frequently talks around this topic but often does so vaguely and indirectly.
\end{abstract}

Keywords: meaning of life; ultimate meaning; pointlessness; everyday meaning

How to cite: Weinberg, R. Ultimate Meaning: We Don't Have It, We Can't Get It, and We Should Be Very, Very Sad. Journal of Controversial Ideas 2021, 1(1), 4; doi:10.35995/jci01010004.

(C) 2021 Copyright by the author. This article is an open access article distributed under the terms and conditions of the Creative Commons Attribution (CC BY 4.0) license.

(c) (i)

\section{Ultimate Meaning}

Some people worry that life is pointless. That's because it is. I don't say that flippantly or glibly. I mean it and I will show it. The "meaning" of life can refer to several different things, including value, explanation, upshot, impact, significance, purpose, or point. ${ }^{1}$ One cause of some confusion in the literature on the meaning of life is that which meaning of "meaning" is being used is not always sufficiently specified, even when the various meanings of the term are acknowledged. I will focus on "point" or "pointlessness," as I take that to capture the essence of the problem of the meaning of life: it's pointless. Not necessarily the things we do or projects we pursue within a life, but the effort or enterprise

1 For a discussion of the many meanings and uses of the term "meaning," especially regarding the meaning of life, see Terry Eagleton, The Meaning of Life: A Very Short Introduction (New York, NY: Oxford University Press, 2008). 
of leading and having lived your entire life—what I call its "Ultimate Meaning;" the point of leading and living a life at all.

Just as the meaning of life is sometimes discussed without sufficiently specifying which meaning of "meaning" is in play, having a "point," is sometimes invoked without sufficient specification. ${ }^{2}$ What exactly does it mean for something to have a point? I suggest that a point is a valued end (be the value objective or subjective) ${ }^{3}$; an enterprise or effort has a point, or is purposeful, if we have justified reason to do it because of its valued end. ${ }^{4}$ Thus, the builder drives the nail into the wood to build a hut for a purpose, an end of value. What ties point to value is the end-regarding reason you build the hut: you build the hut because you value the shelter provided the hut. (And you value the shelter because you value yourself. We can continue to ask about value until we arrive at something that has intrinsic value). In your hut building enterprise, the shelter (or the person enjoying it) is your valued end, or the point of all that building. ${ }^{5}$ Purpose has "value commitments" ${ }^{\prime}$ and involves valued ends. If an enterprise is directed toward or grounded ${ }^{7}$ by an end then the end is being valued; it's the point of the enterprise. This does not entail that seemingly process oriented or atelic pursuits are pointless and not directed toward or grounded by any valued ends. E.g., if we value the process of running or having coffee with friends, it may seem like there are no external ends involved yet we don't find those pursuits pointless. But, even in those cases, the reason we don't find the pursuits pointless is that they do in fact involve valued ends, namely, the exhilarating feeling of running or the joy of intimacy with friends. And those ends, although reached throughout the time engaged in the pursuit, still lie separate from the pursuit itself.

In his discussion regarding living meaningfully, Kieran Setiya distinguishes between telic and atelic pursuits. ${ }^{8}$ Telic pursuits, such as building a house, are aimed at a final end-at completion. Atelic pursuits, such as talking a walk for pleasure, are not aimed at completion or a final state. Setiya argues that many atelic pursuits are not only worthwhile but also crucial to maintaining a sense of meaningful purpose throughout the course of a life. ${ }^{9}$ Indeed, both telic and atelic pursuits can have a point. Both telic and atelic pursuits have, as purposes or points, values that lie outside the pursuits themselves. Atelic activity,

2 David Wiggins helps us get clearer on the meaning of "point" by speaking of points, ends, and values in close enough proximity as to suggest an important relationship between the terms. See Wiggins, "Truth, Invention, and the Meaning of Life," in Needs Values Truth: Essays in the Philosophy of Value (Oxford: Blackwell Publishing Ltd., 1997).

3 You might think that in order for something to have meaning and/or value, it has to be valuable, and not merely valued, because you might think that there is an objective element to meaning and/or value, such that there is no point to my counting the blades of grass on my front lawn even if I think there is, etc. In this discussion, I use what I take to be the weaker, and thus more inclusive standard of value, because I mean to show that Ultimate Meaning is impossible for us, even if we use the more inclusive standard of value. By "human values," I mean whatever values humans legitimately have. I don't argue here for what counts as a legitimate value.

4 For a history and explanation of the concept of purpose, see Michael Ruse, On Purpose (Princeton, NJ: Princeton University Press, 2018).

5 See ibid., 11.

6 See ibid., 99.

7 I say grounded by instead of directed toward an end because purposeful activity need not be "aimed" at any end. Some purposeful pursuits can, instead, be grounded by an end of value, such as keeping a promise, which may be grounded by the value of persons as valued ends. But projects or enterprises tend to be more goal oriented, aimed at ends. I thank Paul Hurley for this point.

8 See Kieran Setiya, "The Midlife Crisis," Philosopher's Imprint 14 (2014): 1-18; and Midlife: A Philosophical Guide (Princeton, NJ: Princeton University Press, 2014), 133-34.

9 See ibid, "The Midlife Crisis," 14-17; and Midlife: A Philosophical Guide, 140-44. 
such as playing with your children, having coffee with friends, or going for a stroll are not pursuits aimed at completion, but they are still pointful because they are grounded by or aim at external values of love, intimacy, joy, etc. When you build a hut, your building is telic, aimed at completion. The shelter is valued because the person who will live in that shelter has intrinsic value and that's the valued end, or the point, of building the hut. Similarly, if you take a walk to get some milk, the walk is telic, aimed at an end. If you walk to enjoy a pleasant stroll, the walk is atelic, not aimed at getting anywhere. But the point of either effort, be it the telic walk or the atelic stroll still lies in a value external to walking itself: the point lies, respectively, in the person enjoying the milk or the sheer joy of ambling about, both of which are external to the actual telic or atelic walking itself.

You might think that you value, say, playing with your children, for its own sake but the play itself is not the valued end-it's not the act of stacking blocks that is itself the point of stacking them. We want to know: why stack blocks? What is our valued end here? The reason we may value stacking blocks with our children is that we value our children, we value the love between us, we value the joy of play, we cherish the intimacy, the knowledge of each other etc., and those values-the children, the intimacy, the knowledge, the joy-are the points or the valued ends of playing with our children, and they are separate from the actual playing. The valued end isn't the playing. It is external to the playing, even if it is attained while playing. The point is not the running, it's the exhilaration derived from it, etc. Things that may be intrinsically valuable, such as happiness, beauty, or truth can serve as valued ends for the effort or enterprise of pursuing happiness, making something beautiful, or acquiring knowledge but they are external to the pursuing, making, appreciating, or acquiring them and that's why they can serve as the point of doing those things or engaging in those efforts. Projects, efforts, and enterprises consist of things we do or pursue, not values. Thus they may be grounded by or aimed at intrinsic values but they remain separate from the valued ends that provide a point to engaging in those pursuits, efforts, projects, or enterprises.

When you're hungry, the point of eating is to enjoy the taste of food and become sated because satiety, you, and enjoyment are valued ends; when you're nice to grandma, the point of your niceness is that grandma and her feelings are valued ends to you. Lots of pursuits, efforts and projects aren't pointless because they are directed toward valued ends. That's the good news. Being nice to grandma is somewhat safe from the perils of pointlessness, at least in my view. So is having coffee with friends, reading a book, getting out of bed, and quite possibly most of the things we do. The only little problem is that the effort or enterprise of leading our entire lives is pointless.

Enterprises or projects are distinguished from isolated acts or merely existing in states, such as being alive or being asleep, by the sustained, coordinated efforts we put forth in a somewhat unified or systematic way, directed toward valued ends. When we consider the project of living of a human life, what's the point of it? Within our lives, we may have lots of pointful or purposeful things to do, from isolated acts to grand projects that can span a good deal of our lives. Many pursuits are purposeful within a life, grounded by or aiming at valued ends within the life, but what is the point of leading a life at all? As we lead our lives, which take lots of effort, and involves, as Thomas Nagel puts it, "decades of intense concern," ${ }^{10}$ what is our justified valued end? Why live?

10 Thomas Nagel, “The Absurd," The Journal of Philosophy 68 (1971): 716-27, 720. 


\section{Why We Can’t Get it}

We cannot possibly have a point to leading a life because valued ends are external to the projects toward which they are directed. Efforts and enterprises need reasons to justify doing them in the form of valued ends in order for them to be purposeful, or have a point. Of pursuits, efforts, or enterprises, we can always ask, "Why do $x$ ?" "Why engage in $y$ ?" Valued ends give us answers in the form of justifying reasons of valued ends, and lie separate from the pursuits or projects. Learning is purposeful because truth is a valued end, building because shelter is a valued end, keeping promises because trust and people are valued ends. A pursuit, effort, or enterprise is not a reason. It needs a reason, a valued end outside of itself, in order for it to have a point. When we question the point of an effort or enterprise, the question is aimed at its end-it is not itself the end; the end is external to it or separate from it. But your life encompasses your entire life and all that you value in it.

The values in your life, e.g., truth, justice, love, etc., may be what you use to guide you in the building and shaping of your life, just as, say, the values of symmetry, beauty, and durability may be the values you use to guide you in the building of a hut. Those values help you understand what makes something a good hut or a good life, and may help you understand how to go about building a good hut or constructing a good life. But they don't tell you why you're doing it in the first place; they don't give you the end-regarding justifying reason, the valued end, or the point of building a hut or a running a life. The point of building a hut, like all points, will lie outside the hut, as we have noted. But there's nothing external to your life to serve as the point of leading and living it because your life includes your whole damn life. Human life includes its entirety, leaving nowhere for us to reach for a valued end to serve as a point for leading and living it.

Because your life includes your entire life,${ }^{11}$ there is nothing external to it to serve as a valued end toward which it is directed. This doesn't mean that your life is worthless or insignificant or not valuable in other ways. It just means that it's pointless.

In his famous paper, "The Absurd," Nagel notes that we can justify acts within a life even if we cannot justify carrying on an entire life:

Chains of justification come repeatedly to an end within life, and whether the process as a whole can be justified has no bearing on the finality of these end-points. No further justification is needed to make it reasonable to take aspirin for a headache, attend an exhibit of the work of a painter one admires, or stop a child from putting his hand on a hot stove. No larger context or further purpose is needed to prevent these acts from being pointless. ${ }^{12}$

He then goes a step further, arguing that just as we ask why we should take the aspirin, we can ask why we should care about our own suffering. He takes this to show that ultimate justification is impossible, and vaguely unnecessary:

We can ask not only why we should take aspirin, but why we should take trouble over our own comfort at all. The fact that we shall take the aspirin without waiting for an answer to this last question does not show that it is an unreal question. We shall also continue to believe, there is a floor under us without waiting for an answer to the

11 Even the afterlife, if it exists, is presumably in some way a part of your life; perhaps its epilogue - otherwise it is hard to see how it counts as your afterlife, but more on that later.

12 See ibid., 717. 
other question. In both cases it is this unsupported natural confidence that generates skeptical doubts; so it cannot be used to settle them. ${ }^{13}$

But here we can distinguish between value skepticism and the problem of life's pointlessness. Taking the aspirin doesn't seem pointless because it's directed toward valued ends, namely, ourselves and therefore our feelings. We can question why we value not suffering but, usually, most find good reasons for this valuing. When questioning why we bother taking the aspirin, Nagel is gesturing at a form of value skepticism. But one need not be a value skeptic to worry about the valued end of the enterprise of life. Value skepticism and the problem of life's pointlessness are separable problems. ${ }^{14}$ Taking an aspirin is directed toward a valued end and therefore is not pointless. The same cannot be said about leading one's life, not because we're value skeptics but because we cannot have an end outside of life to serve as a valued end for leading and living it. Thus, the problem of life's pointlessness does not "suggest thereby that all reasons that come to an end are incomplete." 15 It just suggests, correctly, that all reasons that fail to arrive at a valued end are not reasons that can provide us with a point for an effort or enterprise.

It is helpful here to distinguish between what we might call Everyday Meaning from Ultimate Meaning. Everyday Meaning refers to the value and significance in our everyday lives, including values such as beauty, love, and truth, and the significance of doing things that engage with them. It includes the purpose (i.e., the reason for which something is done) and point (i.e., justifying valued end) of much of our meaningful, everyday lives, which aim at and reflect these valued ends. It includes the impact we have on others and on the world around us, as well as the explanation of our some of our meaningful activities and pursuits. Ultimate Meaning refers to the point of leading a life at all. Why bother with the project, effort, or enterprise of life? What is the valued end of running a human life? Ultimate Meaning is the end-regarding justifying reason, the valued end, or the point of leading a life at all. Distinguishing between Everyday Meaning and Ultimate Meaning makes sense of feeling that life is pointless while still caring very much about everyday matters such as your stubbed toe or your child's first words. It makes sense of finding life pointless yet still caring deeply about other people, our work, and the health of our planet. These sorts of sets of views, which can seem paradoxical, are not all that uncommon, and become understandable once we distinguish between Everyday Meaning and Ultimate Meaning. ${ }^{16}$

13 See ibid., 724.

14 Although true value skepticism entails life's pointlessness (because if we have no values, we can't have valued ends), one need not endorse value skepticism in order to think that life is pointless.

15 See ibid., 718.

16 It is also important to distinguish between Ultimate Meaning and Cosmic Meaning. Cosmic Meaning refers to our meaningful role in the cosmos: to the significance and value of our cosmic niche, to the explanation of our role in the cosmos, our impact on the cosmos, and the purposes or point of the cosmos and our place in it. Additionally, some philosophers think of Cosmic Meaning as the significance or purpose of human life from the standpoint of, or our role in, the universe or the cosmos. David Benatar, for example, finds this lack of Cosmic Meaning central to the kinds of meaning that humans problematically lack. See David Benatar, The Human Predicament (Oxford: Oxford University Press, 2017). This is a very different problem from the one I am addressing here since Ultimate Meaning refers to the point of living a life at all, and that point need not be cosmic. To have Ultimate Meaning, we would need to find a valued end for the project or enterprise of running a human life but there's no reason why that valued end would have to be cosmic or part of a universal purpose or viewpoint. (Sharon Street makes a similar point about normative realism. See Sharon Street, "Nothing Really Matters but That's Not What Matters," in Does Anything Really Matter: Essays on Parfit on Objectivity, ed. Peter Singer (Oxford: Oxford University 
In his later work, Nagel seems to characterize the problem of Ultimate Meaning differently, and more in line with distinguishing Ultimate Meaning from Everyday Meaning:

The problem is that although there are justifications and explanations for most of the things, big and small, that we do within life, none of these explanations explain the point of your life as a whole. ${ }^{17}$

But he maintains the characterization of the problem of Ultimate Meaning as a regression of justification: $x$ gets its meaning from $y, y$ gets its meaning from $z$, and then we have the problem of no ultimate answer to questions of meaning. ${ }^{18}$ And he maintains, as well, that ultimate justification is both impossible and vaguely unnecessary, saying:

What kind of answer would bring all of our "Why?" questions to a stop, once and for all? And if they can stop there, why couldn't they have stopped earlier? ${ }^{19}$

He further argues that the problem of Ultimate Meaning comes from taking an "outside" perspective, explaining, "Looking at it from the outside, it wouldn't matter if you had never existed." 20

But the problem of Ultimate Meaning is not merely a result of the possibility that all justification might be regress-prone (whether or not that is the case), as we can see by the contrast cases of Everyday Meaning, where we do find points—valued ends-to the things we do and projects we undertake. And it doesn't originate from taking a step outside your life to take a peek at it from that "outside" perspective either. Instead, the problem of Ultimate Meaning - its metaphysical impossibility ${ }^{21}$ —results from the nature of points (i.e., that they are separate from the activities, pursuits, projects, and efforts toward which they're aimed) and the nature of a human life (i.e., that it includes its entirety). We can see that problem from right here, from right inside our lives and the effort we put into running them.

For Nagel, when we take a step back and look at human life from an external perspective, we can't find a point to it. And he is correct to think that points involve something external but that externality is not a perspectival one. We can see the pointlessness of living and leading a human life from inside that very effort or enterprise because it is the effort or enterprise itself that demands a point, a justified valued end. The externality that shows us that life is pointless is the externality of values to pursuits, efforts, enterprises, and projects. It is because values lie outside of or external to the efforts or enterprises for which they can serve as a point, and because the effort or enterprise of leading and living a human life includes all of human values, ${ }^{22}$ that we come to realize that living and leading a human life is pointless. It has nowhere outside of its effort or enterprise to reach for a point or valued end for that effort or enterprise.

Press, 2016), 121-48. Conversely, having cosmic significance and impact would not necessarily provide us with Ultimate Meaning, since significance and impact are not necessarily the same as point or purpose. Ultimate Meaning and Cosmic Meaning are separate issues.

17 Thomas Nagel, What Does It All Mean? A Very Short Introduction to Philosophy (New York, NY: Oxford University Press, 1987), 95.

18 See ibid., 96-98.

19 See ibid., 98.

20 See ibid., 95.

21 Thus, Ultimate Meaning is metaphysically rather than conceptually impossible. I thank Thaddeus Metz for urging me to clarify this point.

22 Again, when I say, "human values," I refer to what people value, be the value objective or subjective, etc. (See footnote 3). Our lives include all that we value, regardless of whether the value is objective or subjective, it is still part of, or included in, the enterprise, project, or effort of living and leading a human life. 
We cannot find a valued end for leading a life, or for life itself, and life itself can't be that end since it is the enterprise; it needs a valued end in order to have a point. Life itself is a biological state, not a reason at all, and isn't a reason for leading a life any more than a jump is a reason for jumping or a hut is a reason for building. ${ }^{23}$ It's the joy of jumping or the shelter of the hut that can provide a valued end, a point, for the effort, project, or enterprise. We can have many valued ends within our lives, and they may provide points for many of our efforts within our lives but they can't provide a point to or for leading our lives at all. Our lives may be full, even meaningful, overflowing with purposeful projects and enterprises but conducting life itself isn't one of them. It can't be. There is nothing that lies separate from it to serve as its valued end. This may not seem so bad. If our lives are full of meaningful efforts, projects, and pursuits, who cares about the container in which all this great purposeful, pointful stuff sits? If your life is meaningful, why worry about the meaning of it?

\section{Why Care?}

If all I show is that leading a life is pointless but most of what we do in our lives may not be pointless, that may not seem particularly significant. We may note that many things in life are purposeful and have plenty of value, making life itself a container, of sorts, for valued ends but not the kind of thing that is itself directed toward a valued end. This problem of the meaning of life can lead to a switch from thinking about the meaning of life to thinking about meaning in life and, indeed, much recent philosophical discussion about life and meaning has made that switch. Some important insights and persuasive arguments about meaning in life have been recently made by Susan Wolf's Meaning in Life, ${ }^{24}$ Iddo Landau's Finding Meaning in an Imperfect World, ${ }^{25}$ and Thaddeus Metz's Meaning in Life. ${ }^{26}$ The shift in talk from meaning of life to meaning in life has been at least partially motivated by the sense that it is confused or futile to ask about the meaning of life. However, I argue that it's not confused to ask about the meaning of life, once we specify that we are asking about the point of life and that by point we mean valued end. And it's not futile to ask whether leading and living a human life can have a point; it's just sad because the answer is, unfortunately, no. Life is pointless. Perhaps the shift in focus from meaning of life to meaning in life reflects the view that it is the projects and pursuits within a life that can be pointless or purposeful, meaningful or meaningless. The project or effort of living and leading a human life cannot.

But, while it's important to think about meaning in life, it is also important to think about the meaning of life because we lead one entire life as an effort or enterprise of its

23 Intrinsic value is that which is valuable in itself or for its own sake. We might test for intrinsic value by analyzing whether there is another value on which the value of the thing in question depends. That may be why that which many take to have intrinsic value tends to be abstract, e.g., rationality, happiness, beauty, truth. We may disagree about which specific abstract values are intrinsic but intrinsic value is generally abstract, and can serve as valued ends toward which enterprises may be aimed or by which pursuits may be grounded. Thus, happiness, beauty, and truth are abstract and arguably intrinsic values which can then serve as valued ends for the enterprise of pursuing happiness, making something beautiful, and acquiring knowledge. Life is not a very good candidate for intrinsic value because it's an empirical, biological state, not a value, let alone an abstract value, and it's value can be reasonably questioned (is life worth living?).

24 Susan Wolf, Meaning in Life and Why it Matters (Princeton, NJ: Princeton University Press, 2010).

25 Iddo Landau, Finding Meaning in an Imperfect World (Oxford: Oxford University Press, 2017).

26 Thaddeus Metz, Meaning in Life (Oxford: Oxford University Press, 2014). 
own. In the course of our lives, we can think about how to live, and hopefully arrive at answers grounded by values, perhaps enabling us to live more meaningfully. Aristotle can direct us regarding the constitutive ends of a good life, and how to live well. ${ }^{27}$ Kant can tell us about the fundamental values of valuing oneself and others as ends in themselves that structure a good life. ${ }^{28}$ But those are answers to how best to live. It still makes sense to wonder, why live at all? What is the valued end for that enterprise? We put great effort into it, into the running of our lives as an effort or enterprise of its own and, just as with our other efforts, it makes sense for us to want to see that effort as going somewhere and having a point.

Anyone who dreams and plans for the future, who thinks about how the past fits into their present and future, who thinks about the shape of their life, their reasons for living, the legacy they hope to leave-in other words, anyone who lives a human agential life, is leading a life-running a life-which is an effort, project or enterprise of its own. Our lives, as Velleman has argued, are a story we tell ourselves; we have a narrative identity, we want our lives to make sense as a whole. ${ }^{29}$ But why are we writing a story? Why bother? We are not merely alive, like a bacterium or even a rat; we lead lives, we run our lives as a sustained effort or enterprise, often attempting to fit its pieces together into a purposeful whole. ${ }^{30}$ Not entirely, of course. We may live for the moment sometimes but a life led that way all the time would likely seem fragmentary, incoherent-not only pointless, but centerless, agentless; not a truly human life.

Agency, authorship, and the leading of one's life are human features that can come in degrees and variations. And for those who don't care so much about the overall shape, structure, and purpose of their lives, noting life's pointlessness will perhaps be less devastating. (So they may be merely sad, rather than very, very sad, at our realization about life's pointlessness). Yet we are all human and we all, to some degree, put effort into running our lives as an effort or project of its own.

We run our lives not only in parts but also as an effort of its own. As discussed, enterprises or projects are distinguished from isolated acts or merely existing in states, such as being alive or being asleep, by the sustained, coordinated efforts we put forth in a somewhat unified or systematic way, directed toward valued ends. Which valued ends can serve this role for leading a life? Not just the projects and efforts within it but the project and effort of running the entire it?

If the answer to that question is nothing, then it makes sense to be saddened to realize that. It makes sense to be disappointed that there's no valued end to leading a life at all because, just as we justify our efforts and enterprises within our lives by the valued ends toward which they are directed and would be disappointed to discover that there were no such valued ends, we have the same sorts of reasons to want the leading of the entirety of our lives, the effort or enterprise of $i t$, to be directed toward a valued end. When we discover that this cannot be the case, we have reason to regret this fact; reason to be sad and wish things were different, even though they couldn't possibly be different.

27 See Aristotle, Nicomachean Ethics, trans. Terence Irwin (Indianapolis, IN: Hackett Publishing Company, 1999).

28 See Immanuel Kant, Groundwork for the Metaphysics of Morals, ed. Allen Wood (New Haven, CT: Yale University Press, 2002).

29 See David Velleman, "The Self as Narrator," in Autonomy and the Challenges to Liberalism, eds. John Christman and Joel Anderson (Cambridge: Cambridge University Press, 2005), 56-73.

30 For an excellent discussion regarding the importance of viewing one's life as a whole, in which this point about leading a life rather than merely living is made, see Johan Brännmark, "Leading Lives: On Happiness and Narrative Meaning," Philosophical Papers 32 (2003): 321-43. 
Thinking of your life as a somewhat purposeful enterprise run by you as an agent is one of the things that makes running out of dental floss worth it. Lots of boring, effortful, annoying things, such as keeping yourself in the floss, take up lots of our efforts between the otherwise purposeful projects within our lives. Why do we keep on keeping on? Yes, we have Everyday Meaning, and that is no small thing. It enables us to lead a meaningful life. But it does not negate noticing that there is this other kind of meaning-Ultimate Meaning, which we have reason to want, and it is a sad aspect of the human condition that we cannot have it. There is no contradiction between appreciating Everyday Meaning and wondering, still, why are we bothering to lead a life at all?

You might think that if our lives are suffused with Everyday Meaning, that has to be enough. ${ }^{31}$ What is missing? If my conception of a flourishing life includes appreciating art, baking fluffy as clouds cakes, being a good friend, and a compassionate insurance adjuster, what sense does it make to ask me what the point of having this sort of life is? The point is the Everyday Meaning, the living of this meaningful life. And that's not entirely illegitimate: our everyday activities can be pointful in the everyday sense. And thank goodness for that because, without Everyday Meaning, everyday life might well be unbearable. But I argue that you're not just appreciating art, baking cakes, being a good friend, and compassionately doing your productive and worthwhile job. Your also putting effort and agency into the meta-project, which is the running of your life; conducting the enterprise of living; leading a life. That is an effort or enterprise of its own and not simply the aggregate of your other efforts. So, to the question, how else do we live our lives but in this Everyday sense? In the Ultimate sense, l'd say. It makes sense for us to want that effort, project, and enterprise to have a point of its own. (Aspiration: to every effort, enterprise, project, or job, a point). What is missing, despite Everyday Meaning, is a point for the leading and living our lives as an overall effort of its own. What is missing is Ultimate Meaning. We live our lives in both the everyday and ultimate sense, and it is therefore reasonable for us to want both kinds of efforts to be pointful rather than pointless. That doesn't mean that when we realize we lack Ultimate Meaning we should kill ourselves ${ }^{32}$ or despair of Everyday Meaning. It just means that we recognize a particularly sad aspect of the human condition, which is that we cannot have Ultimate Meaning.

As rational agents, we are inclined toward striving, toward conducting projects or enterprises that are grounded by or aimed at valued ends, and toward leading our entire lives in that way too since it too is an effort or enterprise of its own. Although almost everyone puts effort into running their lives as an effort or enterprise of its own, not everyone does so with the same degree of effort aimed at achieving some kind of overall coherence and purpose. Those of us for whom life is more of an effort than a joy are more likely to find Ultimate meaning especially important because we put a great deal of effort into leading our less than blissful lives and, without a point to it all, that effort can feel like a slog. Those to whom life seems effortless (anyone?) or those who happily treat life like it's the journey rather than the destination that matters are likely somewhat less bothered by a lack of Ultimate Meaning than those of us who find an arduous, perilous, and difficult journey to nowhere distressingly pointless. Some, perhaps the laziest and happy-go-luckiest among us, may even feel relieved to discover that there is no Ultimate

31 I thank Daniel Groll and Thaddeus Metz for pressing me on this point.

32 There can be many reasons to continue living rather than commit suicide, including curiosity about life and events, fear of death, loyalty to family and friends, commitments we have made, and yes, enjoying Everyday Meaning. 
Meaning because that can remove the onus of pursuing it, leaving one more carefree to enjoy the pleasures of everyday life. ${ }^{33}$ Thus, we can recognize some reasonable variation in how much Ultimate Meaning matters to us relative to Everyday Meaning, but Ultimate Meaning still matters quite a bit. ${ }^{34}$ We all put some effort into leading our lives as an effort or project of its own. Part of being a rational agential human is leading one's life, both every day and as an overall effort of its own. Therefore, the fact that we can have Everyday Meaning, while crucial to the meaningfulness of our everyday lives, doesn't somehow solve the problem of the lack of Ultimate Meaning. It makes sense for us to want both.

Having purposeful projects within our lives is surely better than not. Probably much better, and plausibly better relative to the value of our valued ends. The rat pressing the right lever for tastier bits of food has purposeful activity but tasty bits are not as valuable an end for our efforts as is, say, living morally or composing beautifully. Still, not having any valued end toward which the entire enterprise of living and leading a human life is directed makes life a kind of tragic enterprise, even in the face of Everyday Meaning. We've gone from exalted, noble strivers, creators and shapers of the project of life (not merely the projects within life) to mere containers of value: from purposeful constructors of our life stories, with agential unity and worthwhile ends that provide us with reason to live at all, to cups. Sad!

Thus, regardless of the value we can enjoy within our lives, discovering that leading life itself, each of our lives themselves, is pointless should make us sad because it is a fitting response to the facts-i.e., what is the case: that life is pointless-and to our values, i.e., what we have reason to care about: that the leading of our lives have a point in their entirety, that there's a point to the hard, wearying, unified and agential enterprise of leading a human life at all.

\section{Attempts at a Solution to Life's Pointlessness}

Over the millennia that humans have been working so hard and long at leading their lives, I am not the first to notice that life is pointless. Many solutions have been offered, though they are not always easy to follow because different meanings for the problem of the meaning of or in life may be used at different points in the discussion. ${ }^{35}$ But l've specified the problem I'm addressing as the lack of a valued end to the enterprise of life. That can help us analyze solutions that seem to be directed toward that problem (whether they're explicitly formulated that way or not). I will now address solutions that most directly address the problem of the overall pointlessness of the enterprise of leading a life at all. None of them work as solutions, though all of them are quite fascinating and valuable in other ways, including as a coping mechanism, good advice for living a good and perhaps even meaningful life, a vague magical hope, or a compelling way of thinking about the problem.

33 As with so many of the optimistic points in my work, I owe this insight to Saul Smilansky.

34 Landau argues that being too much of a workaholic, or too goal-oriented, can render people particularly vulnerable to what he calls, "the paradox of the end," which is the empty feeling that can occur upon achieving an aim. But when we separate Everyday Meaning from Ultimate Meaning, we can see the legitimacy of being sad to realize that Ultimate Meaning is not attainable, even if we also see that it would be a mistake to then conclude that no form of meaning is attainable. See Landau, ibid.

35 Robert Nozick's discussion of the meaning of life is notable in this regard. It is a wide ranging and fascinating discussion in which the term "meaning" is used very broadly, to mean nearly all the possible meanings of "meaning," at various points in the lengthy discussion. See Robert Nozick, Philosophical Explanations (Cambridge, MA: Harvard University Press, 1981). 


\section{Overview}

Many philosophers who address the problem of the meaning of life recommend hard work toward a valuable, yet likely unattainable, end which extends in some way beyond the individual (or some combination and variation of some of these elements). ${ }^{36}$ It's unclear why the work has to be hard but it seems plausible to think that if it's too easy it may fail to be fully engaging or psychologically fulfilling. Of course, if we're looking for a point to life, the ends that ground it must be valuable so it's clear why the end must be of value. But why must it reach beyond the individual? And why must it be unattainable?

I suspect that the "beyond" recommendation is a way of getting closer to addressing the problem of pointlessness: the reason the goal, end, or grounding value has to be somehow "beyond" the individual is that a point is a valued end, and an end is separate from the effort or enterprise. Thus, for something to serve as a point for leading a life, it has to be in some way separate from or external to it. And, since we can't do, ground by, or aim at anything truly external to our lives because our lives encompass their entirety, the best philosophers can do with this problem is to recommend getting your value as far away from your own little life as possible. Hence, the nearly ubiquitous connection made between meaning and an end beyond yourself: help others, pursue justice, live for god or the afterlife, etc.

Yet, while it's valuable to alleviate suffering or help the downtrodden, we may still wonder about the point of the entire enterprise of these suffering and ameliorating lives, even as we acknowledge the value of helping others once we're all busy living and suffering. Within these lives, we can see the point of alleviating suffering. But why do the whole thing? Why lead and live a human life? The suffering and the ameliorating of the suffering-the whole cycle seems pointless. Many projects that seem to extend beyond the self merely postpone the problem or widen the circle of pointlessness. ${ }^{37}$ Helping others or trying to improve the world for future generations can seem to give us a value outside of our lives, but these are just ways of widening and postponing the problem, as we can see by imagining the world improved enough, then what? What's the point of the rest of your life? (At some point, things are good enough, no? Otherwise, we can seem like slaves to the unending improvement labor, with each generation similarly, drearily, and pointlessly indentured to the next). ${ }^{38}$ Less selfish ends still occur within life and cannot provide a point for the enterprise of living it, as we can see by imagining justice achieved-then what? The world is sufficiently improved, then what? But the problem is not as stark or as in your face as it would be if your end was, say, to play solitaire every day, which is directed toward a valued end that is more clearly well within your sole, personal, everyday life.

Positing god or the afterlife as the point of life are common examples of widening and/or postponing the problem of pointlessness. What's the point of doing god's will or existing in the afterlife? Say we have a blissful afterlife. That can seem like the point of

36 See Johan Brännmark, ibid., 321-43; David E. Cooper, "Life and Meaning," Ratio 18 (2005): 125-37; Antti Kauppinen, "Meaningfulness and Time," Philosophy and Phenomenological Research 84 (2012): 345-77; Iddo Landau, ibid.; Neil Levy, ibid.; Robert Nozick, ibid.; and Susan Wolf, ibid.

37 Levy explicitly notes this as well. See Levy, ibid., 180-81.

38 Samuel Scheffler's account of how future generations provide current generations with meaning is notable in this regard. If he is correct that we "borrow" meaning from the future by imagining our impact on future generations, that can be viewed as a means of postponing the reckoning if we take him to be referring to Ultimate Meaning. His argument is more persuasive when understood as being about Everyday Meaning. See Samuel Scheffler, Death and the Afterlife (Oxford: Oxford University Press, 2013). 
life: to achieve a blissful afterlife. But it really only postpones the question, as we can see by imagining life extending into some sort of afterlife. Okay, you get there, you're happy, now what? ${ }^{39}$ What's the point of the rest of your life/afterlife? Once again, we will note that our lives include their entirety, including their possible afterlife portion, leaving no valued end to serve as a point for living, or afterliving, it. Adding an afterlife epilogue to a regular life just postpones the question by making your life last a lot longer and have this second supernatural chapter.

But why think that an unattainable end is better than an attainable one ${ }^{40}$ That may seem the opposite of what might make life less pointless because what's the point of aiming at something unreachable? It sounds frustrating, at best, and maddeningly pointless at worst. So why recommend this as a way of living a pointful life? I suggest that the reason for this recommendation comes from noting what happens when an end is achieved: then what? If your end is to eat the five tomatoes on your plate and you eat them, what's the point of the rest of your life? You're left to notice that your life encompasses the tomatoes and thus eating those tomatoes cannot save your life from pointlessness. But if eating the tomatoes is a valuable end then walking towards them may feel purposeful and you may not notice that all that walking hasn't made your life's entirety any less pointless until you reach the table, sit down, and eat them. Thus, the more unlikely it is that you will ever reach those tomatoes, the more likely it is that you will not be confronted directly with the fact that pursuing the valuable end of getting to them does not make your life any less pointless. But the fact remains. The same applies to loftier, more valuable, and more other-regarding ends. If your end is helping others or achieving justice, think about what would happen if those ends were met. You would feel great for a bit, and then wonder: Now what? You would notice that the valued end of helping others or living in a just society occurs within your life, is encompassed by your life, and therefore cannot serve as a valued end for leading it. ${ }^{41}$ It seems that the unattainability of the end serves to mask its ultimate failure to provide Ultimate Meaning rather than to actually provide your life with Ultimate Meaning.

(Another problem with needing our valued ends to be unattainable in order for our lives to have a point is the contradiction it forces us into: we have to want what we claim not to want, e.g., we have to want injustice or suffering to persist so that we have something unattainable to fix or alleviate but the injustice and the suffering are supposedly the things we are trying to eliminate because we don't want them).

You might wonder about seemingly inexhaustible values we can aim at, such as, say, love. Perhaps unattainable is just the wrong term to use for the kinds of values

39 This reasoning implies a tedium to immortality, which is a point raised by Bernard Williams and responded to by Nagel. See Bernard Williams, "The Makropolous Case: Reflections on the Tedium of Immortality," in Problems of the Self (Cambridge: Cambridge University Press, 1973), 82-100; and Nagel, "Death," in Mortal Questions (Cambridge: Cambridge University Press, 1979), 1-10.

40 The importance of the unattainability of the goal is a point made and expanded upon by Levy, ibid. and the crisis of meaning that can be caused by attaining a goal is addressed by both Levy ibid.; Landau, ibid., chapter 11, "The Paradox of the End," 145-62; and Julian Baggini, What's It All About: Philosophy and the Meaning of Life (Oxford: Oxford University Press, 2007), Chapter 5. Elijah Milgram makes the point differently, arguing that aiming at a point for leading life as a whole-what he might call a "project life"-is doomed to failure and therefore a mistake. See Milgram, Mill and the Meaning of Life (Oxford: Oxford University Press, 2019).

41 Thus, when discussing helping others as the answer to the meaning of life, Baggini challenges this claim by noting that it implies that when everyone has been helped, we will have nothing to live for, and is therefore a self-defeating view. See Baggini, ibid. 
that can provide a point to living a life at all. Perhaps inexhaustible values can serve as sources of Ultimate Meaning, without leaving us at a "now what?" point. ${ }^{42}$ But I am skeptical of the plausibility of inexhaustible values and therefore think it is no accident that philosophers have recommended unattainable goals instead. It seems that, for any value, we can reach a saturation point or an achievement point beyond which more of that value ceases to be valuable to us. Beyond a satisficing point of justice, living for it or continuing to pursue it would seem pointless and counterproductive; nitpicky, annoying, not valuable. Even love, if we had too much of it, might begin to feel smothering or, at some point, irritating, overwhelming, or just too much. (I can imagine ending a relationship for reasons of this sort). There is even a documented phenomenon of seeing something so cute that you can't stand it and want to obliterate it. ${ }^{43}$ I therefore think unattainable is no misnomer for the recommendations in the literature on wrestling with a sense of life's overall pointlessness. ${ }^{44}$

I will now discuss some solutions to the problem of life's pointlessness in greater detail.

\section{Leading Lives}

Several philosophers have noted the importance that the narrative trajectory of a human life plays in leading a meaningful life. Antti Kauppinen argues that meaningfulness is a function of the structure of an agent's goal-directed activities, which satisfies the human agential pride of being the protagonist in pursuit of a valuable goal. ${ }^{45} \mathrm{He}$ concludes that, "life is ideally meaningful when challenging efforts lead to lasting success," 66 ideally beyond the individual herself. Kauppinen frames his discussion in terms of human good and exemplars of meaningful lives, and he defines meaningfulness as "appropriateness of feelings of fulfillment and admiration." ${ }^{77}$ Within the context of his argument, he is certainly correct to note that ends are important components of meaningfulness and that, when thinking about human meaningfulness, the agential unity and narrative trajectory of human lives are crucial factors. They contribute to the meaningfulness of the narrative. But why write the story? What is the valued end for the writing or living of the entire life story, a story which encompasses its own end and cannot really last beyond its last page, so to speak? What Kauppinen makes clear, however, is that, for people, meaningfulness

42 One can read Setiya as recommending engaging with inexhaustible values as a way to avoid or better handle a midlife crisis, though it is more accurate to say that he recommends engaging with atelic rather than telic pursuits, as explained earlier. See Setiya, "The Midlife Crisis," ibid., 14-17; and Midlife: A Philosophical Guide, ibid., 140-44.

43 See John Hamilton, "When Cute is Too Much, the Brain Can Get Aggressive," National Public Radio, Morning Edition, December 31, 2018.

44 The reasoning here also applies to the suggestion that the point of leading and living a life might be to try to make life maximally valuable by maximizing the objective values within it. That is because the same way we can see that maximizing justice, for example, cannot serve as life's point once we imagine attaining it and also because we see that it is unlikely that there are values that are better and better the more of them we pursue or attain, we can see that adding additional values to the mix does not change anything about these problems. Just as justice doesn't work as the point for running your life, justice and love don't work either, etc. I also wonder about the concept of a maximally valuable life, especially as applied to the effort, project, or enterprise of running your life. This seems like a variant of the container solution, which I discuss in Section V.

45 See Kauppinen, ibid.

46 Kauppinen, ibid., 346.

47 Kauppinen, ibid., 346. 
demands a point. We want our projects to be directed toward valued ends, and want the leading of our lives to have a point, a valued end.

Both Levy and Brännmark focus on the fact that people lead lives as central to the pursuit of meaning and they note as well both the importance of having ends, and the difficulty of finding an end that can provide a point for leading or living a life.

Brännmark argues for placing purposefulness at the center of accounts of human good because we don't merely live, we lead lives and, therefore, he says, a good human life involves purposive narrative meaning, or a point. ${ }^{48}$ Since the valued end should ideally be of great value, we do better, he argues, when pursuing grand goals, such as love, truth, and justice, which provide worthwhile ends for us, even though he concedes that there's no answer to the skeptic about "purposive meaning." ${ }^{49}$ Even worse, he notes that if you become too absorbed with the singular pursuit of one of those ends of great value, you can lose individuality-your very narrative soul!-and become, "like a cog, losing the rationale for this life being yours to lead." 50,51

Here too we are getting closer to the problem: to the fact that people lead lives and want that enterprise to being going somewhere, to be directed toward something, to have a point, a valued end. But we still don't find any solution or facing up to the sadness of the impossibility of a solution. Sure, justice and truth are ends so abstract and difficult to achieve that, like tomatoes situated very far away, we may notice less that our lives encompass our efforts toward those valued ends, but encompass them they do nonetheless. ${ }^{52}$ Those ends can only provide purposes for projects or efforts within our lives but they cannot provide a point to or for leading our lives at all.

The problem we face when we achieve an end only to notice that our lives encompass it and have themselves no valued end may be what motivates Levy to argue that meaningful lives are attained through hard work that we cannot imagine completing. ${ }^{53}$ Because the pursuit of a meaningful end can seem to be rendered meaningless in its achievement (e.g., Sisyphus's rock stays on top of the mountain-then what?, Levy asks), in our pursuit of a valued end for life, "nothing will fail here like success." 54 Thus, Levy recommends the pursuit of valued ends such as justice, art, or truth, toward which we can make incremental progress but never achieve or even be able to fully imagine achieving:

Since we cannot know what the final goal might be like, we cannot imagine completing our project, and therefore we cannot be shaken by the image of its completion. ${ }^{55}$

48 Brännmark, ibid.

49 Brännmark, ibid., 339.

50 Brännmark, ibid., 340 .

51 Milgram uses the example of John Stuart Mill's "project life," as he calls it, to make a similar point about the self-defeating nature of lives lived as the singular pursuit of one end or goal. See Milgram, ibid.

52 We can also note that there is an alternative conception of values, such as truth or justice, that may make more sense than thinking of justice or truth as the point of your life. Not only are your efforts encompassed by your life, and not only do you risk effacing your life entirely if you give it all up on the altar of justice, but there's also the question of whether justice or some other such value is something to live for or something to live in accordance with. Living for justice can seem to give your life a valued end but only until you realize that once a fair or just society is achieved, then what? Your life goes beyond that, it encompasses it, and therefore it cannot be the point of your life. It seems more appropriate to think of living your life in accordance with values such as justice or truth rather living your life with them as final valued ends (perhaps this is one way of putting one of the many arguments against consequentialism).

53 See Levy, ibid.

54 This is one of the most penetrating observations anyone has ever made on this topic. Levy, ibid., 182.

55 Levy, ibid., 185. 
This may work to help us not realize that our lives are pointless but only by placing the tomatoes so far away that they are even out of the reach of our imagination, so to speak. This seems less like a satisfying solution and more like a method for being less compelled to face the problem. Our failure of imagination does not save our lives from pointlessness, it can only save us from effectively imagining or realizing that our lives are pointless. Yet pointless they remain.

\section{The Mysterious, Ineffable "All"}

As argued, the externality of a valued end is often the implicit factor motivating discussions of meaning as connecting to something beyond the individual. Cooper argues that for $x$ to be meaningful, it has to relate to meaningful $y$, which gets it meaning from meaningful $p$, etc. Therefore, living a human life itself must get its meaning from something beyond it: "human existence is meaningful only if it is 'answerable' to what is 'beyond human'."56 Otherwise, says Cooper, we are struck by the possibility that our efforts are pointless. But what is the beyond human to which human existence is answerable to? Here Cooper argues that the best we can do is to accept that the answer must be "mysterious, ineffable," the noumena that we can't see. ${ }^{57}$

Robert Nozick also articulates the problem of meaning as a problem of moving goal-posts, or a regress that we find ourselves in when seeking a point to life. Even when pursuing valued ends, he argues that we can still ask what our lives amount to and whether the ends have any significance or meaning. ${ }^{58}$ I have argued that when we ask what are lives amount to, we aren't necessarily being value skeptics-we aren't necessarily questioning whether, say, it is valuable to appreciate art or love our children. Instead, we may be noticing that these valued ends occur within our lives and don't provide us with a valued end to the enterprise of living and leading our lives at all. But Nozick sees a regress indicating a problem of limits. Whatever we do toward value within our lives, he says:

... we can still ask what it all amounts to .... We can distance ourselves from the life, see it as the particular things it was, notice its limits, and wonder whether really it has any meaning. ${ }^{59}$

Thus, Nozick concludes:

The problem of meaning is created by limits, by being just this, by being merely this ... However widely we connect and link, however far our web of meaningfulness extends, we can imagine drawing a boundary around all that, standing outside looking at the totality of it, and asking, 'But what is that meaning of that, what does that mean?' ... To see something's limits, to see it as that limited particular thing or enterprise, is to question its meaning ... In imagination, we stand outside the thing and ask for the meaning of the totality. ${ }^{60}$

Since Nozick puts the problem of meaning in terms of limits, it follows that he sees the solution as somehow limitless. When seeking a point to our lives, Nozick recognizes

56 David E. Cooper, "Life and Meaning," Ratio 18 (2005): 125-37, 126.

57 See Cooper, ibid., 132

58 Nozick, ibid.

59 See Nozick, ibid., 578-79.

60 See Nozick, ibid., 595-98. This way of putting the problem of meaning has some similarity to Nagel's articulation of the absurd as resulting from being able to transcend our limits in thought, to stand outside ourselves, and question the meaning of our lives. See Nagel, "The Absurd," ibid. 
that, "Once you come to feel your existence lacks purpose, there is little you can do." 61 That is correct! He should have stopped there, and let the tragic reality sink in. Instead, he invokes the Kabbalistic concept of Ein Sof, literally meaning "there is no end," or limitless, and metaphorically meaning pure god, the infinite, boundless, ${ }^{62}$ to gesture toward Ultimate Meaning as perhaps somehow being Ein Sof, as that which needs no connection to anything else to have meaning. Because it's limitless, there is no place to stand separate from it and question its meaning, and it can therefore "stand as its own meaning." ${ }^{63}$ This idea is reminiscent of some Kabbalistic ${ }^{64}$ and Buddhist ${ }^{65}$ views of life as ultimately aiming to merge into one infinity. ${ }^{66}$ And from within that infinity, there is no external standpoint from which to ask for justification, purpose, or point. (Nagel also sometimes seems to wonder whether, if there were a solution to the problem of Ultimate Meaning, it would have to work that way, as does Benatar, at times). ${ }^{67}$

This is an intriguing conception of the problem of meaning or pointlessness but I think it gets things exactly backward. The problem of pointlessness is not that we can stand outside the project and question its point-that's fine as long as we have an answer to that question, as we often do (as discussed): e.g., the point of eating is to eliminate the suffering of hunger, and enjoy the taste of food. We can stand outside these efforts and question the value of their ends by asking, "Who cares if you're hungry?" "Why care about suffering?" but we find answers fairly readily available: we value ourselves because we are rational, moral agents and/or because we have interests, and since others are similar in relevant ways, we value them and their feelings. If we don't care about anything, we are committed to extreme value skepticism, contradicted by the nearly universal values of avoiding suffering, and valuing many positive feelings. The problem of life's pointlessness is not that we're able to ask the question about valued ends. It's that we can't find an answer, because nothing lies separate from it to serve as its valued end. We may value avoiding suffering but the point of leading a life can't be to avoid suffering because why then bother with the whole thing? (And if we manage to avoid suffering, then what?) What is the point of bothering to lead a human life? What is the valued end to the project, enterprise, and very hard work of leading a human life? If we extend ourselves or connect

61 See Nozick, ibid., 588.

62 See http://www.jewishvirtuallibrary.org/ein-sof. See Nozick, ibid., 600-10.

63 See Nozick, ibid., 604.

64 See Daniel Chanan Matt, The Essential Kabbalah: The Heart of Jewish Mysticism (Aukland, New Zealand: Castle Books, 1997).

65 See Hiroshi Obayashi, ed., Death and the Afterlife: Perspectives of World Religions (Westport, CT: Praeger, 1991), Part III: Death and the Afterlife in Eastern Religions.

66 A connection to infinity is also implicated in Tolstoy's turn to religion for enduring meaning. See Leo Tolstoy, A Confession (London, UK: 1879, Penguin Classics Reprint 1988). Tolstoy's The Death of Ivan Ilyich explores similar themes (though it also includes more existentialist themes of authenticity and facing the reality of death) (New York, NY: 1886, Bantam Classics Reissue, 1981).

67 In What Does it All Mean? Nagel considers: "Can there really be something which gives point to everything else by encompassing it, but which couldn't have, or need, any point itself? Something whose point can't be questioned from outside because there is no outside?" (Oxford: Oxford University Press, 1987), 100. In The Human Predicament, Benatar reasons somewhat similarly about temporal limitlessness, arguing that if we had no temporal limits then "the purposes internal to your life might well suffice" because there would be no limit to transcend (ibid., 56). However, as I argue here, we arrive at the problem of Ultimate Meaning from the fact that we are engaging in an effort, project, or enterprise of living a life, and that nothing lies outside of the enterprise of life to serve as a point for living it because your life includes its entirety. A less limited enterprise would make finding something external to it harder, not easier. 
ourselves to something limitless, infinite, or boundless, all we do is extend the space from which we cannot draw an answer (because our enterprise now occupies that space, indeed all space, and seeks a valued end to that whole, now hugely infinite, situation). But we do not make it impossible or nonsensical or beyond our imagination to ask the question. The question comes from inside the enterprise, no matter how expansive it is. The question of a point arises from the fact that we are engaging in an enterprise, regardless of how limited or unlimited it may be. And our lives, be they limited or limitless, still include their entirety, leaving us no answer to the question about their valued end. If our lives or we ourselves were less limited, we would restrict the space from which we might be able to draw an answer to the question of the valued end of life's enterprise, but we would not thereby eliminate or answer the question.

Our lives remain pointless. That fact remains sad.

I will now address some objections.

\section{Objections}

\section{Everyday Meaning}

Some might think that Ultimate Meaning lies in providing us with the opportunity to achieve Everyday Meaning. After all, if we did not lead our lives, we could not engage with Everyday Meaning. In this way, our overall effort at leading a life can be seen as a necessary condition for Everyday Meaning and, therefore, the point of leading and living our lives would be that this is necessary for attaining Everyday Meaning. However, while serving as a necessary condition for Everyday Meaning might give our lives Everyday Meaning, it won't give leading our lives at all a point, because the values we aim at in our meaningful everyday pursuits cannot serve as points for leading our lives at all, and, therefore, serving as necessary conditions for those same values can't either.

Recall: if I work as a lawyer fighting for civil rights, for example, the point of my efforts is justice, which is part of my Everyday Meaning. But justice cannot serve as the point of leading my life, even if we think of our overall efforts as necessary conditions for my Everyday Meaningful fight for justice, as I will notice by imagining justice achieved, - then what? What is the point of the rest of my life? (Sisyphus's rock doesn't roll back down. And then? We are faced with the fact that getting it up isn't the point of Sisyphus's life since his life goes on, it contains the rock, wherever he gets it to stay, etc.). My life contains the justice in it and that's why justice cannot serve as a point for the all-encompassing effort of leading or running the enterprise of life; it cannot provide Ultimate Meaning.

Aha, you might say, but without the life you are working so hard to lead, you would have no container, so to speak, for the justice you value. Perhaps the point of life is to serve as a container for the points or valued ends of our everyday pursuits. I turn now to this possibility.

\section{The Container Solution}

Instead of seeing the project of leading a life as a pointless container, as I alluded to earlier, one can argue that the point of the project of leading a life is to provide a container for all the valuable ends within a life, just as the point of any container is to hold the stuff in 
it. ${ }^{68}$ Containers aren't pointless - their point is to contain things. So why not be happy to realize that your life is a container for all the valuable things in it?

Because the point of a container is not simply to contain things because what is the point of containing things? The point of containers is to contain things in service of the point of other pursuits or projects. The point of a cup is to hold the coffee so that you can drink it. Without a container, the coffee is all over the place and very hard to drink. So the cup operates in service to your valued end of enjoying the taste and stimulating effects of coffee. Your sock drawer is similar: it contains your socks, thereby making it easier for you to find them and have a less chaotic life. The value of the sock drawer lies outside the drawer and its sock contents - it lies in you, the person outside the drawer whose life is improved by having a container for their socks. When we apply this container logic to life itself we run into the same problem we had in the first place-that there's nothing outside of it or external to it to serve as an end of value. The purposeful ends are not within; not in the cup or the drawer or the life-container.

If running your life is containment service, like a coffee cup or a sock drawer, what's the point of it? What's the point of containing coffee, socks, or truth? If we think that your life as a container of value has a point because the justice or truth in it are valuable and you couldn't have that without having a life to put it in, we can wonder, just as we did before, whether justice or truth can be the point of life. And we can then note, just as noted earlier, that they can't be, as we see when we imagine justice achieved or truth attained-then what? We are left, once again, to realize that since justice or truth occur within a life, are values within a life, they cannot serve as ends of value for the arduous enterprise or effort of running a life. We return to the fact that ends of value do not lie within. The container solution doesn't work.

It can seem like the answer because it can seem to take our point outside our life activities, such that the point isn't, say, justice itself, which occurs within a life and so can't serve as the point of leading a life, but the containment of justice, which seems more like the enterprise of leading a life itself. But we then have to ask about the point of containing things and we are back to where we started from-to the coffee, the socks, and the justice, which are all valuable but still don't serve as the valued end, or the point, of containing them. The problem with thinking that life's point is being a container of value is that when we question which values make that containment pointful, we find that none are external to the enterprise of running a life so none can serve as a valued end for that containment. ${ }^{69}$

\section{Seeking a Point to Life Is a Category Mistake}

We might consider asking for the point of life, or being sad that there isn't one, to be a category mistake, akin to asking, "When is a potato?" or being sad that your baby has a

68 A variant of the container solution is the view that the point of leading your life is simply the aggregate of the points of the things you do within your life. On this view, the point of the meta-project of running your life is to have or be able to achieve all of the pointful things you do within your life. This makes the running of your life meaningful insofar as it is the place to put or accumulate all of your Everyday Meaning. In other words, it is a form of the container solution, subject to the same problems the container solution faces.

69 One might also wonder whether the point of life can be to "collect" (as opposed to merely contain) value. The same problems apply to this version of the container solution: what is the point of being a collector of value? That what one collects has value? We are back to looking to the collected or contained values-to the truth, justice, or love within one's life that cannot serve as a point for the enterprise of living a life because ends of value are external to the project or enterprises toward which they are aimed or by which they are grounded. 
name but not a number, or that your nose is neither odd nor even (even if it's both unusual and symmetrical). Potatoes don't have times, and noses aren't even or odd. What sense would it make to be sad about that? Seeking the "when" of a potato or the oddness or evenness of a nose is incoherent; potatoes and noses are not the kinds of things that have times or oddness/evenness. It is incoherent to demand that of them and nonsensical to bemoan the fact that your nonsensical demands cannot be met. When we ask what the point of life is and are sad to discover that life can't have a point, are we making a category mistake? Are we nonsensically bemoaning an incoherence?

I don't think so. Leading a human life is an effort or enterprise we all engage in, just as we engage in many other projects within our human lives. It can then come as a disappointing surprise to note that, unlike many other of our purposeful enterprises, leading life itself cannot have a point. Asking whether life is pointless is not incoherent-we understand the question and are capable of sensibly answering it; we just may not like the answer. It's more similar to a ninety-nine-year-old man being sad that he can no longer run a marathon in under two and a half hours than it is to a numberless baby. The fact that ninety-nine-year-old men are not the kinds of things that can run marathons in less than two and half hours (at least not yet) doesn't make asking whether they can a nonsensical category mistake nor does it make it a category mistake to bemoan the fact that they can't.

\section{The Fallacy of Composition}

One might object that seeking a point to living at all is an instance of the fallacy of composition, i.e., of attributing to the whole what is true of the parts. ${ }^{70}$ But, as argued, life is an effort or enterprise that we engage in both in parts and as an effort or enterprise of its own. It therefore makes sense for us to want that effort to have a point because it is the valued ends toward which our efforts are directed that serve to help us justify or makes sense of those efforts.

\section{Agency?}

When we speak of living a life — the effort or enterprise of running or leading our lives —one might wonder whether we may be referring to the act or effort of being an agent, which might aim at the end value of agency or autonomy. Could the value of agency be the point of leading a life? I don't think so because the value of agency doesn't make just any exercise of it valuable or purposeful. The value of autonomy or agency doesn't confer value or a point to just anything you do autonomously or as an agent. Agency may be valued but it won't provide us with a valued end for living because it doesn't answer the question: As an agent, why do this? Why lead and live a life?

\section{Fun!}

Who cares if life is pointless? It's delightful! Well, maybe for you, and even maybe-er for you your whole life. Some people suffer nearly all the time and nearly all people suffer some of the time. I suppose some may find life so enjoyable that they don't care whether it's pointless. However, given how much people suffer in life, I find that view staggeringly insufficient. But, even if life were more similar to a pleasure trip, it would still be sad that it

70 I thank Paul Hurley for raising this objection. 
was a pointless pleasure trip because, as leaders of lives, it makes sense for us to want our work to be going somewhere, or directed toward something, rather than pointless, even if pleasurably so.

\section{Meaning Superstars}

What about people such as Martin Luther King Jr., Jonas Salk, or Beethoven? It seems ludicrous to say that their lives were pointless. The point of Martin Luther King Jr.'s life was to advance civil rights, the point of Jonas Salk's life was to prevent polio, the point of Beethoven's life was to create music so sublime that it still makes our hearts burst hundreds of years later. No? No.

When thinking about people of extraordinary achievement and heroism, I think we become star struck and somewhat confused. These historical heroes are such superstars in other aspects of non-Ultimate Meaning, such as significance, impact, and values within a life (e.g., justice, knowledge, art, and benevolence) that we may be so overwhelmed by how meaningful their lives are in so many aspects of Everyday Meaning that we are reluctant to deny them any aspect of meaning, even Ultimate Meaning. But even for the superstars, we can ask about the valued end of them conducting the enterprise of their lives. We may find it less pressing to have an answer to that question when they shine so brightly in other dimensions of meaning. But they still lack this one. Imagine if Jonas Salk, or Nelson Mandela lived for hundreds or even thousands of years past their heroic accomplishments: we might then also imagine them wondering what is the point of leading and living their lives, overall. If we imagine our meaning heroes living centuries past their accomplishments, we can then see the question of Ultimate Meaning emerge more clearly, when not overshadowed by an exceptionally meaningful accomplishment within a life.

\section{Live for Others}

If leading your life can't have an overall point for yourself, maybe it can serve as a part of someone else's purpose, thereby allowing you a derivative purpose for your life. Living as a footstool for a great artist or living as an expression of god's creativity are examples of these kinds of derivate purposes or points one might think one's life can have. Maybe god is intrinsically good and so are god's purposes, maybe the great artist's valuable art will be of higher quality because she had a great footstool to support her.

These do seem to be potential ways of your life serving a purpose. The problem is it wouldn't be your purpose; it would be god's or the artist's. A shame for you to live as a mere means to other people's purposes. I don't think that counts as a point for you leading and living your life. You might as well be living someone else's life.

Moreover, note that these sorts of solutions are just variations on the "living beyond yourself" recommendation for meaningfulness I noted earlier, when I noted that positing god or the afterlife as the point of life are common examples of widening and/or postponing the problem of pointlessness. What's the point of doing god's will or existing in the afterlife? Less selfish ends still occur within life and cannot provide a point for the enterprise of living it, as we can see by imagining the great artist's masterpiece achieved-then what, my dear footstool? (We're just moving the tomatoes). 


\section{It Doesn't Matter If Life Is Pointless}

I have argued that life's pointlessness is sad for us. Not all agree. Nagel, for example, takes his conclusions about life's absurdity in stride. He notes that ironic resignation is an appropriate response to life's absurdity and argues that no great angst is merited because if nothing matters then it doesn't matter that nothing matters. ${ }^{71}$ That is a confused conclusion. The view that if nothing matters then it doesn't matter that nothing matters is as facile as it sounds and is based on nothing more than an equivocation about the term, "meaning": When we are sad to notice that nothing matters, we are sad that life doesn't have a point. Telling us that this tragic fact doesn't "matter" is telling us that this tragic fact is of no significance. But, of course it is significant. How could finding out that life is pointless be considered insignificant? It devalues our striving, our agency, and the lives we work so hard to lead. If we don't equivocate between the "pointless" and "insignificant" senses of the word "meaning," we don't find ourselves in the Nagelian wonder-world where life is pointless but we have no reason to mind.

\section{It's Futile or Pointless to Be Sad about Life's Pointlessness}

Why be sad about life's pointlessness? Is that not also pointless? You might think that lamenting life's pointlessness is futile, and itself pointless, like crying for the moon. If you can't do anything about it, why bemoan it? Uh, because it's sad. We may value truth regardless of its prudential or instrumental value in a particular instance. There is dignity in facing the facts, and humanity in responding with appropriate sadness to sad facts. Sometimes, wishing for or lamenting the impossible is silly, like crying for the moon, or being sad that you're not a number. But, when the impossible would be great for us, and when its absence leaves us lacking something it makes sense for us to want, then it is fitting for us to be sad and disappointed.

John Shand argues that, "if life is pointless and everything we do without value, then there can be no more value in a life that faces up to that truth than in one that doesn't," 72 and to argue otherwise is to insist that although nothing has value, facing that truth does have value. But accepting that leading a life is pointless does not commit one to the view that nothing has value; it only commits one to the view that life is not directed toward a valued end. That doesn't mean that nothing in life or anywhere else in the vast universe has no kind of value at all. It doesn't entail that truth has no value, or that discovering and acknowledging truth has no value.

\section{Conclusion}

I have argued that "point" is one of the meanings of "meaning," and that a point is a valued end. I have also argued that our grand enterprise of leading a life, of living at all, cannot have one. This does not entail value skepticism, but it's still pretty sad, as value conclusions go. We may have valued ends within life, but the fact that leading a human life at all is pointless can cast a pall over the pursuits within it that seem otherwise valuable or purposeful. (Putting little meaning bits or even grand meaning chunks into our pointless life container is not what we thought or hoped we were doing with all of our efforts, is it?) Let us acknowledge what we are facing here: Running a life, conducting a life, living a life,

71 See Nagel, ibid., 727.

72 See John Shand, "How to Live," The Journal of the Royal Institute of Philosophy 82 (2007): 347-48. 
is a tragic enterprise. One cannot help but strive and struggle and try to make something of it, of yourself; but, sadly, it is ultimately and invariably pointless.

Acknowledgments: Special thanks to Yuval Avnur, David Boonin, Daniel Groll, Joey Gruman, Chris Heathwood, Paul Hurley, Iddo Landau, Masahiro Marioka, Thaddeus Metz, Dion Scott-Kakures, and Saul Smilansky, for very helpful discussion and written comments. Thanks to audiences at the 2018 Rocky Mountain Ethics Congress, the University of Haifa, the 2nd International Conference on Philosophy and Meaning in Life at Waseda University, and the Brooklyn Public Philosophers' speaker series, for helpful discussion. Thanks to the anonymous referees and the editors of this journal for helpful comments. 